\title{
Population structure and gene flow in Stomion: a species swarm of flightless beetles of the Galápagos Islands
}

\author{
TERRIE L. FINSTON* \& STEWART B. PECK \\ Department of Biology, Carleton University, Ottawa, Ontario, Canada, K1Y 5P4
}

\begin{abstract}
Stomion is a swarm of 13 flightless tenebrionid beetle species endemic to the Galápagos Islands. Their distribution is patchy and largely restricted to the littoral and arid zones of the archipelago. Each taxon is found on one or a few geographically close islands. Thirty-five populations representing nine of the taxa were examined at eight polymorphic enzyme loci using cellulose acetate electrophoresis to measure patterns of gene flow and investigate models of dispersal in a relatively young species group exhibiting spatially isolated populations.

Genetic subdivision is high, particularly among populations of taxa which inhabit more than one island, revealing restricted gene flow and confirming the high potential for reproductive isolation among subpopulations. The mean $F_{\mathrm{ST}}$ across taxa was 0.30 . The genetic differentiation occurring between spatially isolated populations may explain the exuberant speciation of the genus in the Galápagos. Tests of gene flow models give support to the stepping-stone model of dispersal. Because of their lack of flight wings, interisland dispersal of Stomion probably occurred by oceanic drift as pleuston or on floating debris, with individuals colonizing nearby islands more frequently than ones at a greater distance.
\end{abstract}

Keywords: allozymes, beetles, Galápagos Islands, gene flow, population genetics.

\section{Introduction}

The extent of isolation and gene flow among spatially separated populations determines the potential for genetic differentiation, reproductive isolation and speciation. The resulting population differentiation may result from heterogeneous selection on disjunct populations or the stochastic effects of finite population size and genetic drift. Thus, an analysis of population structure and gene flow is an essential first step towards understanding the relative effects of selection and drift in producing the observed population differentiation. In addition, patterns of geographical allelic variation in members of a species complex may provide insight into past evolutionary events affecting the evolution of the group.

The migration of individuals may be measured using both direct and indirect methods. Mark and recapture studies can be used to measure individual vagility and provide estimates of the number of migrants between populations. Alternately, population genetic structure can be used to estimate levels

*Correspondence: Department of Zoology, University of Guelph, Guelph, Ontario, Canada, N1G 2W1. of gene flow and infer levels of migration. Two models of gene flow are commonly used. The rare alleles model of Slatkin (1985) uses the average frequency of alleles found only in single subpopulations (private alleles) to infer the amount of gene exchange between those subpopulations. Wright's $F$ statistics (1978) offer an additional method of measuring genetic differentiation among subpopulations whereby the fixation indices of subpopulations with respect to the total population are calculated.

Generally there is a predictable relationship between individual vagility and population subdivision; sedentary organisms tend to show higher values of $F_{\mathrm{ST}}$ whereas more vagile organisms show lower values (Zera, 1981; Liebherr, 1986). Data from several recent studies have provided estimates of gene flow through the examination of population genetic structure in beetles which have localized distributions as a result of host-plant specificity (McCauley \& Eanes, 1987) or habitat restrictions (King, 1987; Crouau-Roy, 1989). The present study supplements a field mark and recapture study (Finston, 1993) which suggested that individual vagility was limited in three genera of flightless tenebrionid beetles among quadrats at a single site and provides 
a test of gene flow levels in beetles restricted to island habitats.

Island and island-like communities provide models for studying the genetic effects of isolation and population subdivision, and their roles in microevolutionary genetic change. The Galápagos Islands have been available for colonization for approximately 3-4 million years (Hall, 1983; Hickman \& Lipps, 1985), and like other isolated archipelagos they are rich in endemic faunas. In particular, three genera of flightless tenebrionid beetles comprise the greatest endemic beetle assemblage in the islands (Peck \& Kukalova-Peck, 1990). Of these, the radiation of the endemic genus Stomion Waterhouse is believed to have occurred following colonization by a single ancestral species, which has since become extinct (Van Dyke, 1953). The limited dispersal ability and patchy distribution of this species swarm of flightless tenebrionid beetles provides an ideal model for characterizing population subdivision.

G.R. Waterhouse erected the genus Stomion in 1845 to encompass three new species from collections made by Charles Darwin in 1835. The most recent comprehensive taxonomic treatment of the genus (Van Dyke, 1953) recognized eight species and two subspecies. Three additional subspecies were subsequently described (Von Kaszab, 1970; Franz, 1985). The genus is widespread in the archipelago but each taxon is found on only one or a few islands which are geographically close (Van Dyke, 1953; Finston, 1993). Members of the genus are found primarily in the low elevation littoral and arid zones of the islands where the substrate is generally sand or cinder.
In the present study, cellulose acetate electrophoresis was employed to examine the population structure of the genus Stomion. Beetles from 35 sites were examined at eight variable enzyme loci with an aim towards understanding patterns of gene flow and models of dispersal in a young insect species swarm showing spatial subdivision.

\section{Materials and methods}

\section{Electrophoresis}

Samples of beetles were made at 35 sites on 19 different islands. Individuals were identified to species using the key of Van Dyke (1953). Eight of the 13 described taxa were available for analysis. In addition, one population, DARW, represented a taxon which could not be placed in the existing key. Large islands were sampled at several sites whereas smaller islands were generally represented by only a single collection site. The sites and the sample sizes used for electrophoretic analysis are shown in Table 1 and site locations are shown in Fig. 1. Live beetles from each of the 35 sites, representing nine taxa, were frozen on dry ice and shipped to the laboratory in Ottawa where they were stored in a $-80^{\circ} \mathrm{C}$ ultrafreezer until further analysis. Variation at enzyme loci was analysed using cellulose acetate electrophoresis. This technique permitted individuals to be examined for variation at multiple enzyme loci. Cephalic tissue of dissected individuals, rather than thoracic or abdominal tissue, was analysed, because the latter often contained food particles or eggs and caused interference with allozyme banding patterns.

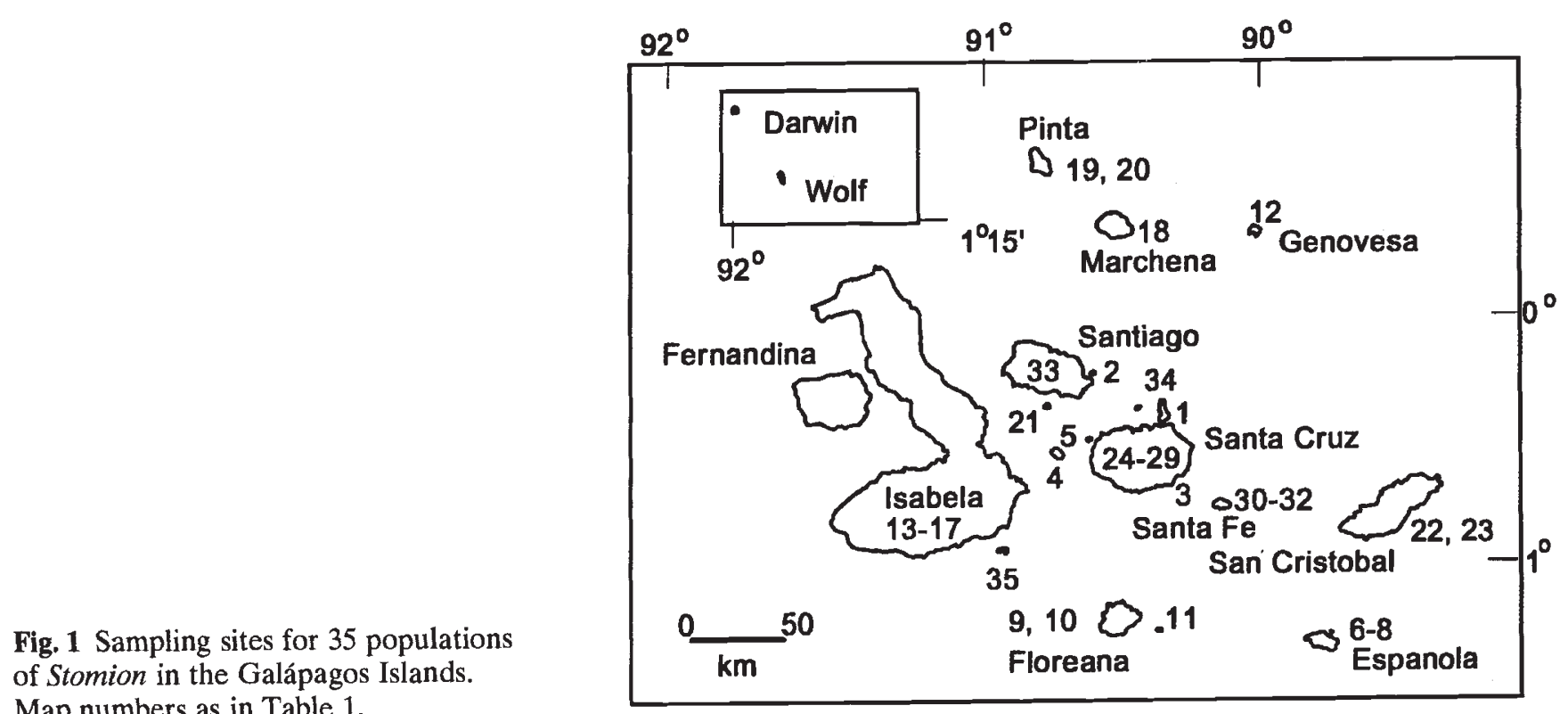
Map numbers as in Table 1. 
Table 1 Sites and sample sizes $(N)$ used in the electrophoretic examination of Stomion

\begin{tabular}{|c|c|c|c|c|}
\hline Island & Site & $N$ & Taxon & Map no. \\
\hline Baltra & BALT & 44 & S. linelli & 1 \\
\hline Bartolomé & BART & 44 & S. linelli & 2 \\
\hline Daphne & DAPH & 49 & S. linelli & 4 \\
\hline Eden & EDEN & 15 & S. linelli & 5 \\
\hline Rabida & RABI & 12 & S. linelli & 21 \\
\hline \multirow[t]{2}{*}{ Santa Cruz } & GRAN & 44 & S. linelli & 26 \\
\hline & SHOR & 15 & S. linelli & 29 \\
\hline Seymour & SEYM & 13 & S. linelli & 34 \\
\hline \multirow[t]{3}{*}{ Española } & BGAR & 37 & S. g. punctipennis & 6 \\
\hline & MANZ & 50 & S. g. punctipennis & 7 \\
\hline & PTSU & 44 & S. g. punctipennis & 8 \\
\hline \multirow[t]{2}{*}{ Floreana } & FLBB & 9 & S. g. galapagoensis & 9 \\
\hline & FLCU & 38 & S. g. galapagoensis & 10 \\
\hline Gardner & GARD & 36 & S. g. galapagoensis & 11 \\
\hline Genovesa & DARW & 25 & 'Genovesa' & 12 \\
\hline Caamaño & CAAM & 42 & S. laeviagtum & 3 \\
\hline \multirow[t]{2}{*}{ Isabela } & ARIM & 44 & S. laevigatum & 13 \\
\hline & TAGU & 43 & S. laevigatum & 16 \\
\hline Santa Cruz & BTOR & 44 & S. laevigatum & 25 \\
\hline Santiago & SGPE & 44 & S. laevigatum & 33 \\
\hline \multirow[t]{3}{*}{ Isabela } & WVIL & 16 & S. longulum & 17 \\
\hline & AZUL & 44 & S. longulum & 14 \\
\hline & NVIL & 44 & S. longulum & 15 \\
\hline \multirow[t]{3}{*}{ Santa Cruz } & BARR & 44 & S. longulum & 24 \\
\hline & HALF & 4 & S. longulum & 27 \\
\hline & PENS & 44 & S. longulum & 28 \\
\hline Marchena & MARC & 38 & S. rugosum & 18 \\
\hline \multirow[t]{2}{*}{ Pinta } & FORE & 18 & S. rugosum & 19 \\
\hline & IBET & 36 & S. rugosum & 20 \\
\hline \multirow[t]{2}{*}{ San Cristóbal } & AERO & 30 & S. helopoides & 22 \\
\hline & LIDO & 33 & S. helopoides & 23 \\
\hline \multirow[t]{3}{*}{ Santa Fé } & SFEB & 44 & S. obesum & 30 \\
\hline & SFEP & 9 & S. obesum & 31 \\
\hline & SFTR & 16 & S. obesum & 32 \\
\hline Tortuga & TORT & 30 & S. obesum & 35 \\
\hline
\end{tabular}

Map numbers refer to Fig. 1.

One reference standard (an individual of $S$. linelli Blair from Isla Daphne) was included in each row of 12 individuals for comparison of electromorph mobilities. In addition, on some gels, four individuals from a site were carried over to the next set of gels to provide a second source of comparison of electromorphs.

Electrophoresis was carried out using standard methods (Murphy, et al., 1990; Hebert \& Beaton, 1993). Two buffer systems were employed: Tris-glycine $(\mathrm{pH} 8.5)$ was used for all enzyme systems except $6 P g d h$, for which Tris-citrate $(\mathrm{pH} 7.3)$ was employed.

Initially, 174 animals from six different sites were analysed for 20 commonly resolvable loci (Hsiao,
1989; Hebert \& Beaton, 1993) to identify informative loci. Eight variable loci were found in the pilot study: hexokinase (Hk-2), mannose-6-phosphate isomerase (Mpi), phosphoglucomutase (Pgm-1), peptidase-A (Pep, utilizing phe-pro), glutamate oxaloacetate transaminase, supernatant and mitochondrial forms (Got-s, Got-m), 6-phosphogluconate dehydrogenase (6Pgdh) and phosphoglucose isomerase (Pgi). Where possible, 44 individuals from each site were analysed for these eight loci. The protein products of these presumptive gene loci were visualized using staining protocols outlined in Hebert \& Beaton (1993) and Murphy et al. (1990). The resulting bands were scored with respect to their relative mobilities: the slowest migrating electromorph was 
assigned a one; larger numbers indicated faster mobility.

\section{Data analysis}

Analyses of electrophoretic data were carried out using BIOsys-1 (Swofford \& Selander, 1991) except where indicated. Allele frequencies were calculated for each site by direct count. Genotype frequencies were tested against Hardy-Weinberg expectations using a $\chi^{2}$ goodness-of-fit test. Levene's (1949) correction for small sample sizes was employed. To correct for errors resulting from multiple tests of the same hypothesis, the probablility values were adjusted using the sequential Bonferoni procedure (Rice, 1989; Lessios, 1992). Gene flow was measured in two ways. Firstly, hierarchical $F$-statistics were calculated at two levels to examine gene frequency divergence among subpopulations (Wright, 1940). The hierarchy was constructed such that differentiation among sites on a single island and among islands were tested for each species. The number of migrants was estimated from $F$-statistics using the following formula:

$F_{\mathrm{ST}}=1 /\left(4 N_{\mathrm{m}}+1\right)$,

where $N_{\mathrm{m}}=$ effective number of migrants per generation. Secondly, the rare allele model of Slatkin (1985) was used to estimate gene flow using the frequency of unique alleles among demes. Slatkin's formula relies on the assumption that the frequency of unique alleles in subpopulations is a measure of the number of migrants between subpopulations:

$\ln [p(1)]=a \ln \left(N_{\mathrm{m}}\right)+b$,

where $p(1)$ is the average frequency of alleles found only in single populations and $a$ and $b$ are constants that depend on the population size. In order to use Slatkin's constants $a$ and $b$, which were based on a sample size of $25, N_{\mathrm{m}}$ was multiplied by the ratio $25 / n$, where $n$ is the mean sample size of those populations possessing unique alleles (Slatkin, 1985, 1987).

To examine modes of dipersal, three models of gene flow were examined: an isolation-by-distance model whereby migrants disperse more frequently to demes in close proximity, and less frequently to distant demes, resulting in a positive correlation between geographical and genetic distance; a stepping-stone model, whereby migration occurs only between adjacent demes, resulting in greater genetic similarity between populations which are adjacent; and an island model, where migration occurs at random among demes, and there is no correlation of genetic relatedness to either geographical distance or physical adjacency. Patterns of geographical variation were tested using the Mantel test (Sokal, 1979). A matrix of Rogers's (1972) genetic distance measures (GEN) for all pairwise comparisons of sites was tested against matricies measuring the geographical characteristics of those sites. Three matricies of geographical relationships were constructed. The first (GEO) used absolute distances in kilometres between all site pairs to test the isolation-by-distance model. The remaining two matrices were used to test the stepping-stone model and were constructed with different stringencies for assignment of neighbouring sites. The first (ADJ-1) used a binary adjacency matrix whereby site pairs were considered neighbours only if they occurred on the same island. These were given a value of one and site pairs which were located on different islands were assigned a zero. The second binary matrix (ADJ-2) was less stringent: site pairs within a $50 \mathrm{~km}$ radius of one another, regardless of island, were given a value of one and site pairs which fell outside of the $50 \mathrm{~km}$ radius were assigned a zero.

Scaling of genetic distances in two dimensions was performed using the MDS module of SYSTAT (Wilkenson, 1988) on Rogers's distances of two taxa ( $S$. longulum and $S$. laevigatum) to examine spatial relationships among populations for taxa represented by sites on more than one island, as well as by multiple sites on single islands. Rogers's distance measure was chosen because multidimensional scaling requires metricity of the data (Swofford \& Olsen, 1990).

\section{Results}

Allele frequencies for all sites are available from the authors. A $\chi^{2}$ contingency analysis showed that for four taxa there were significant frequency differences among sites (Table 2).

Population genotype frequencies were compared with those expected by Hardy-Weinberg predictions for each polymorphic locus. Of 153 tests against Hardy-Weinberg predictions, 36 (23.5 per cent) were found to violate predictions. In each case, the deviation resulted from heterozygote deficiency.

There was substantial genetic subdivision among sites in some Stomion taxa (Table 3). Wright's hierarchical $F$-statistics showed that for most taxa genetic differentiation was high among sites, particularly among those sites occupying different islands. On average, for all sites within a taxon, about 30 per cent of the total variation in allele frequencies was the result of genetic differentiation between sites 
Table 2 Chi-square contingency analysis of allele frequency differences averaged over eight polymorphic loci among populations of the eight Stomion taxa represented by more than one sampling site

\begin{tabular}{lccrrr}
\hline Taxon & $\begin{array}{c}\text { No. of } \\
\text { islands }\end{array}$ & $\begin{array}{l}\text { Mean no. } \\
\text { of alleles }\end{array}$ & $\chi^{2}$ & d.f. & $P$-value \\
\hline S. g. galapagoensis & 2 & 3.3 & 18.76 & 4.57 & 0.237 \\
S. g. punctipennis & 1 & 3.4 & 4.12 & 4.86 & 0.121 \\
S. helopoides & 1 & 4.0 & 18.20 & 3.00 & 0.036 \\
S. laevigatum & 4 & 4.1 & 246.90 & 15.71 & 0.010 \\
S. linelli & 8 & 4.0 & 108.08 & 18.00 & 0.008 \\
S. longulum & 2 & 3.9 & 172.32 & 14.28 & 0.013 \\
S. obesum & 2 & 4.3 & 80.12 & 9.86 & 0.095 \\
S. rugosum & 2 & 2.7 & 34.51 & 3.43 & 0.135 \\
\hline
\end{tabular}

Table 3 (a) Wright's hierarchical $F$-statistics combined across loci for each taxon represented by sites on more than one island. (b) Non-hierarchical $F$-statistics for species represented by sites on single islands

\begin{tabular}{|c|c|c|c|c|c|c|c|c|c|}
\hline $\begin{array}{l}\text { (a) } \\
\text { Subgroup }(S)\end{array}$ & Total group $(T)$ & lae & lon & obe & gal & rug & $\operatorname{lin}$ & $\begin{array}{l}\text { (b) } \\
\text { pun }\end{array}$ & hel \\
\hline Site & Island & 0.368 & 0.380 & 0.264 & 0.162 & 0.021 & 0.134 & 0.135 & 0.059 \\
\hline Site & Total & 0.395 & 0.440 & 0.284 & 0.089 & 0.359 & 0.216 & - & - \\
\hline Island & Total & 0.050 & 0.096 & 0.027 & 0.087 & 0.345 & 0.094 & - & - \\
\hline$N_{\mathrm{m}}$ (Wright) & & 0.383 & 0.318 & 0.630 & 2.56 & 0.446 & 0.907 & 1.60 & 3.99 \\
\hline
\end{tabular}

lae: Stomion laevigatum; lon: $S$. longulum; obe: $S$. obesum; gal: $S$. g. galapagoensis; rug: $S$. rugosum; lin: $S$. linelli; pun: $S . g$. punctipennis; hel: $S$. helopoides.

(mean $F_{\mathrm{ST}}=0.297$ ). Approximately 70 per cent of the variation resulted from differences within sites $\left(1-F_{\mathrm{ST}}\right)$. Within a taxon, there was less genetic differentiation between sites on the same island than between all sites (mean $F_{\mathrm{ST}}=0.190$ ). Furthermore, those taxa which are found only on single islands, $S$. galapagoensis punctipennis and $S$. helopoides, showed some of the lowest levels of genetic differentiation between sites (mean $F_{\mathrm{ST}}=0.097$ ). Using Wright's $F_{\mathrm{ST}}$ to calculate the number of migrants, $N_{\mathrm{m}}$, we found that migration was substantial ( $>1$ migrant/ generation) in three taxa, $S$. helopoides, $S$. galapagoensis punctipennis and $S$. galapagoensis galapagoensis. The numbers of migrants as estimated by Slatkin's rare alleles model were generally in concordance with those calculated from Wright's $F$ statistics, with two exceptions (Table 4). Most notably, $S$. longulum appeared to have modest migration among demes according to Slatkin's model $\left(N_{\mathrm{m}}=1.74\right)$ whereas migration appeared to be rare using Wright's model $\left(N_{\mathrm{m}}=0.318\right)$. Similarly, for $S$. linelli, Wright's model produced $N_{\mathrm{m}}=0.907$ whereas Slatkin's model produced $N_{\mathrm{m}}=3.71$.

Gene exchange resembled the stepping-stone model of dispersal: individuals were most likely to migrate to nearby demes. The results of Mantel's test showed a significant relationship between genetic distance and both measures of island adjacency but no significant relationship between genetic distance and geographical distance (Table 5). Multidimensional scaling of intraspecific genetic distances confirmed the trend that geographically close sites showed higher genetic affinities (Fig. 2).

\section{Discussion}

The genus Stomion is primarily restricted to the low elevation, vegetated arid zone habitats on the islands in the Galápagos Archipelago, resulting in spatial isolation of populations. Opportunities for dispersal are further reduced by the flightless condition of the genus. A study involving mark and recapture of individuals belonging to three flightless tenebrionid genera (Stomion, Ammophorus Gúerin-Méneville and Blapstinus Latreille) at a single site showed that while the number of recaptured individuals was low, individuals were invariably recaptured in the same quadrat in which they were marked (Finston, 1993). In addition, active searches outside the quadrat area produced no marked beetles. The study failed to resolve reliable estimates of population sizes; how- 
Table 4 Average frequencies of unique alleles $p(1)$ and estimates of $N_{\mathrm{m}}$ for eight taxa of Stomion using Slatkin's rare alleles model

\begin{tabular}{lccl}
\hline Taxon & $N$ & $p(1)$ & $N_{\mathrm{m}}$ \\
\hline S. laevigatum & 43.2 & 0.103 & 0.417 \\
S. longulum & 31.9 & 0.058 & 1.74 \\
S. obesum & 24.6 & 0.135 & 0.426 \\
S. g. galapagoensis & 28.5 & 0.051 & 2.54 \\
S. rugosum & 30.4 & 0.228 & 0.125 \\
S. g. punctipennis & 42.2 & 0.059 & 1.28 \\
S. helopoides & 31.2 & 0.084 & 1.08 \\
S. linelli & 27.7 & 0.043 & 3.71 \\
\hline
\end{tabular}

Table 5 Results of Mantel's test for geographical variation of allele frequencies among eight taxa of Stomion

\begin{tabular}{lcrrrr}
\hline Test & $N$ & \multicolumn{1}{c}{$Z$} & \multicolumn{1}{c}{$Z_{\text {exp }}$} & \multicolumn{1}{c}{$\sigma^{2}$} & $P$-value \\
\hline GEN-ADJ-1 & 35 & 13.53 & 32.55 & 3.10 & 0.004 \\
GEN-ADJ-2 & 35 & 102.12 & 143.78 & 32.91 & 0.004 \\
GEN-GEO & 35 & 1767.80 & 1562.42 & 1635.28 & 0.996 \\
\hline
\end{tabular}

$N$ : number of populations; $Z$ : Mantel statistic; $\sigma^{2}$ : variance; $P$ : probability.

Matrix abbreviations are as follows GEN: Rogers's genetic distance; ADJ-1: binary adjacency matrix, sites on same island considered adjacent; ADJ-2: binary adjacency matrix, sites within $50 \mathrm{~km}$ of one another considered adjacent; GEO: geographical distance matrix.

ever, field collections of Stomion at sites throughout the archipelago showed that population sizes ranged from very small (6.1 Stomion collected per personhour at the Tortuga site) to large (110 Stomion per person-hour at the Caamaño site). Low dispersal ability, in conjunction with finite population sizes and the patchy distribution of suitable habitats, sets the stage for substructuring to occur in localized populations.

This study clearly showed that sampling sites represented distinct inbreeding populations and that population substructuring was substantial in most taxa. Allele frequencies are significantly different among populations for four of the taxa, including one, $S$. helopoides, which is found on only a single island. Approximately 20 per cent of genotype frequencies at variable loci in Stomion populations showed deviations from Hardy-Weinberg expectations as a result of a heterozygote deficit. A deficiency in heterozygotes from inbreeding is predicted when population sizes are small and dispersal is limited. Wright $(1977,1978)$ showed that in highly structured populations, migration does not provide
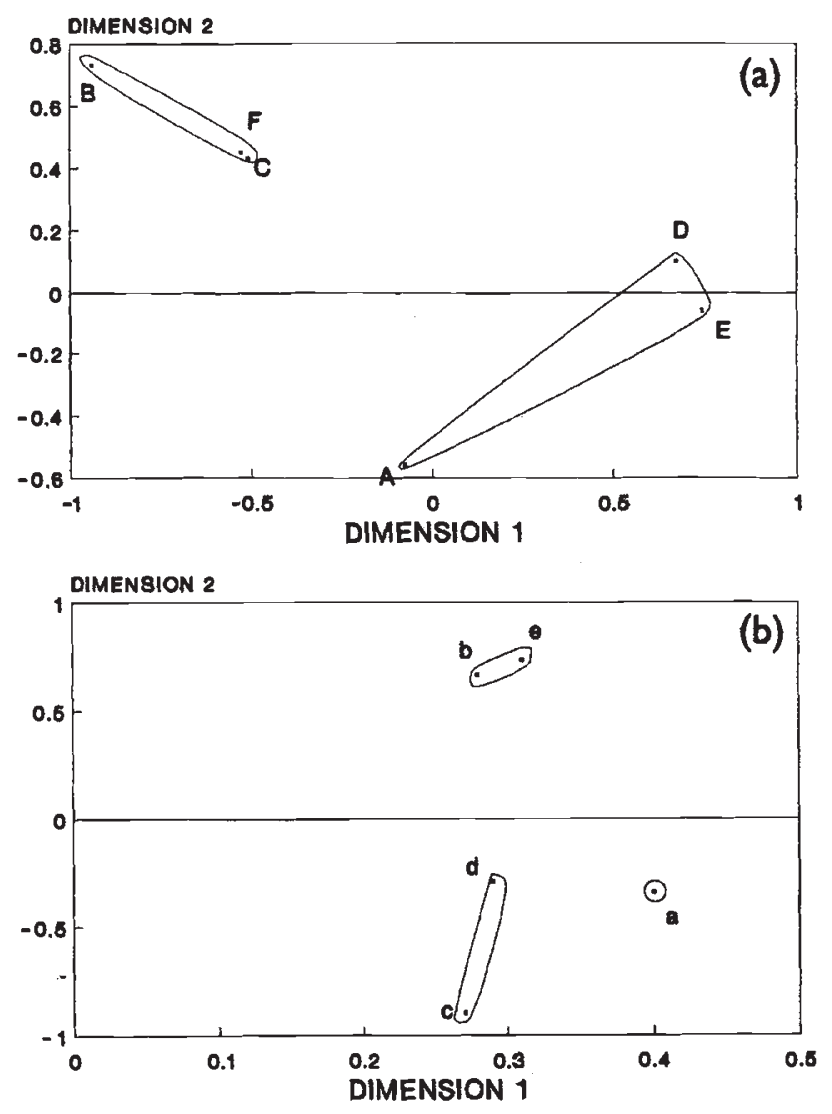

Fig. 2 Scaling in two dimensions of Rogers's genetic distance of populations of (a) Stomion longulum and (b) $S$. laevigatum. Populations are circled by island; site names as in Table 1. Santa Cruz: A, BARR; D, PENS; E, HALF; c, BTOR; d, CAAM (satellite island approximately $1 \mathrm{~km}$ from Santa Cruz); Isabela: B, AZUL; C, NVIL; F, WVIL; b, TAGU; e, ARIM; Santiago: a, SGPE.

substantial levels of gene flow to overcome the effects of selection and genetic drift.

Wright's $F$-statistics further confirmed that there was significant inbreeding within Stomion populations, and restricted gene flow among populations. From 9 per cent to 44 per cent of the overall genetic variation in eight of the taxa was attributable to differences between populations and the number of migrants between populations was generally fewer than one per generation. The number of migrants was greater than one for both Wright's and Slatkin's estimates of migration in just three taxa: $S$. helopoides, S. g. punctipennis and $S$. g. galapagoensis. The two former taxa are restricted in distribution to single islands whereas the latter is found only on the island of Floreana and its small offshore satellite island, Gardner. In contrast, the estimated number of interpopulation migrants was lowest in those taxa which occupy geographically distant islands such as 
S. laevigatum, which is found on the islands of Santa Cruz and Isabela. However, populations on the same island also showed high levels of genetic subdivision in some taxa. Genetic differentiation among highly subdivided populations may be evidence of incipient speciation and provides a model for the allopatric radiation of the genus in the archipelago.

Geographical barriers imposed by large water gaps clearly affect dispersal in flightless beetles but other barriers to dispersal may also exist. For example, five distinct races of the Giant Tortoises inhabit each of five volcanoes on Isabela. In this case, the young, barren low elevation lava fields between volcanic uplands present geographical barriers to gene exchange (Marlow \& Patton, 1981). The highly stratified vegetation zones on the islands (Wiggins \& Porter, 1971) may pose additional geographical barriers to these flightless beetles. The habitats to which the genus is restricted lie mainly along the perimeter and on the leeward side of islands and are separated by the wetter habitats found at higher altitudes and on the windward side of the high islands.

While it is clear that gene flow between sites on the same or different islands is restricted in some taxa, the role of local selective pressures must also be considered in explaining the observed variation in population structure as it is difficult to assign population genetic characteristics unequivocally to random or selective events (Slatkin, 1987). Differences in allele frequencies among populations, even those on the same island, are consistent both with the pattern of limited gene flow and differing selective pressures among neighbouring populations. While the level of interpopulation migration may not be sufficient to overcome the stochastic effects of random genetic drift and finite population sizes, further genetic differentiation may have been promoted by differential selection imposed by the varied enviroments of the different zones and islands. While individual taxa of the genus Stomion occupy similar vegetation zones on different islands, Bowman (1961), in his study on the adaptive characteristics of Darwin's finches, was able to show that the islands in fact possessed unique and endemic floras. Furthermore, the upper limits of the vegetation zones may vary by as much as $100-200 \mathrm{~m}$ on the same island, depending on the juxtaposition of the site with respect to the direction of the prevailing winds (Wiggins \& Porter, 1971), and some vegetation zones are lacking altogether on some islands.

Colonization of new demes fits the stepping-stone model of dispersal whereby gene exchange occurs most often between adjacent demes. Mantel's test of geographical characteristics with genetic relatedness showed a significant correlation between genetic distance and both measures of site adjacency. This relationship was further confirmed by multidimensional scaling of genetic distances for populations of two taxa, $S$. longulum and $S$. laevigatum, in which populations occupying the same island clustered more closely than populations from different islands. Because these flightless beetles rely on passive modes of interisland dispersal, new colonizations are most likely to occur on islands in close proximity to the parent population. Little is known about the ability of tenebrionids to survive or remain afloat in salt water, although one study showed that beetles remained afloat and alive in the Baltic Sea for 5 days (Palmen, 1944). Recent studies by Peck (1994a,b) showed that Coleoptera are present as both aerial plankton and sea-surface pleuston between the islands of the Galápagos. Howden (1977), in his study of beach drift in New South Wales, Australia, showed that after storms, drift and vegetation mats which washed ashore were often vehicles for many heavy-bodied beetle families. The distance a migrant can travel to colonize a new island is dependent on the rate and direction of oceanic currents and the number of days an individual can remain alive during transport. Certainly, adjacent down-current islands are the most favourable for the arrival of drifting beetles.

Clearly, limited dispersal ability in conjuction with the patchy distribution of suitable habitats has played a key role in the allopatric isolation of Stomion populations. As a result, spatial subdivision of populations has promoted random genetic drift, inbreeding and localized adaptation, resulting in morphological and genetic differentiation among members of the genus. Ultimately, this may explain the exuberant radiation of Stomion in the archipelago. In addition, high levels of substructuring within taxa may be evidence of incipient speciation.

\section{Acknowledgements}

F. Cepeda and A. Izurieta, Superintendents, Galápagos National Park (Department of Forestry, Ministry of Agriculture, Republic of Ecuador) issued scientific research permits. Field logistical support was provided by the Charles Darwin Research Station, Santa Cruz Island, D. Evans and C. Blanton, Directors. Field work was partially supported by a research grant to S.B.P. from the Natural Sciences and Engineering Research Council of Canada and an OGS award to T.L.F. Richard Perry provided assistance with the electrophoresis. Field sampling 
was aided by Sandra Abedrabbo, Joyce Cook, Moraima Inca, Bernard Landry, Ricardo Palma, Richard Perry and Eduardo Villema. The manuscript was improved by comments from Marc Boileau and two anonymous reviewers.

\section{References}

BOWMAN, R. I. 1961. Morphological differentiation and adaptation in the Galápagos finches. Univ. Cal. Publs. Zool., 58, 1-302.

CROUAU-ROY B. 1989. Population studies on an endemic troglobitic beetle: geographical patterns of genetic variaton, gene flow and genetic structure compared with morphometric data. Genetics, 121, 571-582.

FINSTON, T. L. 1993. Evolution of the genus Stomion (Coleoptera: Tenebrionidae) in the Galápagos Islands. M.Sc. Thesis, Carleton University, Ottawa, Ontario.

FRANZ, H. 1985. Beitrag zur Kenntmis der Koleopterenfauna der Galápagos-Inseln. Entomol. Situngsber. Oster. Akad. Wiss. Math. Naturwiss. Kl. Abt. I., 194, 73-124.

HALL, M. L. 1983. Origin of Española and the age of terrestrial life on the Galápagos Islands. Science, 221, 545-547.

HEBERT, P. D. N. AND BEATON, M. J. 1993. Methodologies for Allozyme Analysis using Cellulose Acetate Electrophoresis, 2nd edn. Helena Laboratories, Beaumont, TX.

HICKMAN, C. S. AND LIPPS, J. H. 1985. Geologic youth of Galápagos Islands confirmed by marine stratigraphy and paleontology. Science, 227, 1578-1580.

HOWDEN, H. F. 1977. Beetles, beach drift, and island biogeography. Biotropica, 9, 53-57.

HSIAO, T. H. 1989. Estimation of genetic variability amongst Coleoptera. In: Loxdale, H.D. and den Hollander, J. (eds) Electrophoretic Studies on Agricultural Pests. Systematics Association Special Volume No. 39, pp. 143-180. Clarendon Press, Oxford.

KING, P. s. 1987. Macro- and microgeographic structure of a spatially subdivided beetle species in nature. Evolution, 41, 401-416.

LESSIOS, H. A. 1992. Testing electrophoretic data for agreement with Hardy-Weinberg expectations. Mar: Biol., 112, 517-523.

LEVENE, H. 1949. On a matching problem arising in genetics. Ann. Math. Stat., 20, 91-94.

LIEBHERR, J. K. 1986. Comparison of genetic variation in two carabid beetles (Coleoptera) of differing vagility. Ann. Entomol. Soc. Am., 79, 424-433.

MCCAULEY, D. E. AND EANES, w. F. 1987. Hierarchical population structure analysis of the milkweed beetle, Tetraopes tetraophthalmus (Forster). Heredity, 58, 193-201.

MARLOW, R. W. AND PATTON, J. L. 1981. Biochemical relationships of the Galápagos Giant Tortoises (Geochelone elephantopus). J. Zool. Lond., 195, 413-422.

MURPHY, R. W., SITES, J. W., BUTH, D. G. AND HAUFLER, C.
H. 1990. Proteins. I. Isozyme electrophoresis. In: Hillis, D.M. and Moritz, C. (eds) Molecular Systematics, pp. 45-126. Sinauer Associates, Sunderland, MA.

palmen, E. 1944. Die anemohydrochore Austbreitung der Insekten als zoogeographischer Faktor. Ann. Zool. Soc. Zool. Bot. Fenn. Vanamo., 10, 1-262.

PECK, S. B. 1994a. Aerial dispersal of insects between and to islands in the Galápagos archipelago, Ecuador. Ann. Entomol. Soc. Am., 87, 218-224.

PECK, S. B. 1994b. Sea-surface (pleuston) transport of insects between islands in the Galápagos archipelago, Ecuador. Ann. Entomol. Soc. Am., 87, 576-582.

PECK, S. B. AND KUKALOVA-PECK, J. 1990. Origin and biogeography of the beetles (Coleoptera) of the Galápagos Archipelago, Ecuador. Can. J. Zool., 68, 1617-1638.

RICE, w. R. 1989. Analyzing tables of statistical tests. Evolution, 43, 223-225.

ROGERS, J. S. 1972. Measures of Genetic Similarity and Genetic Distance, pp. 145-153. Studies in Genetics. VII. University of Texas Publication 7213.

SLATKIN, M. 1985. Rare alleles as indicators of gene flow. Evolution, 39, 53-65.

SLATKIN, M. 1987. Gene flow and the geographic structure of natural populations. Science, 236, 787-792.

SOKAL, R. R. 1979. Testing statistical significance of geographic variation patterns. Syst. Zool., 28, 227- 232.

SWOFFORD, D. L. AND OLSEN, G. J. 1990. Phylogeny reconstruction. In: Hillis, D. M. and Moritz, C. (eds) Molecular Systematics, pp. 411-501. Sinauer Associates, Sunderland, MA.

SWOFFORD, D. L. AND SELANDER, R. B. 1991. BIOSYS-1. $A$ Computer Program for the Analysis of Allelic Variation in Genetics. Department of Genetics and Development, University of Illinois at Urbana-Champaign, Urbana, IL.

VAN DYKE, E. C. 1953. The Coleoptera of the Galapagos Islands. Occasional Papers of the California Academy of Science No. 22. pp. 1-181.

VON KASZAB, z. 1970. Coleoptera Tenebrionidiae. In: Leleup, N. and Leleup, J. (eds) Mission Zoologique belge aux iles Galápagos et en Ecuador, vol. II, pp. 183-210. L'Imprimerie des Sciences, SA, Brussels.

WIGGINS, 1. L. AND PORTER, D. M. 1971. Flora of the Galápagos Islands. Stanford University Press, Stanford, California.

wilkenson, L. 1988. systat: The System for Statistics. SYSTAT, Evanston, IL.

WRIGHT, s. 1940. Isolation by distance. Am. Nat., 74, 232-248.

WRIGHT, s. 1977. Evolution and the Genetics of Populations, vol. 3, Experimental Results and Evolutionary Deductions. University of Chicago Press, Chicago.

WRIGHT, s. 1978. Evolution and the Genetics of Populations, vol. 4, Variability Within and Among Natural Populations. University of Chicago Press, Chicago.

ZERA, A. J. 1981. Genetic structure of two species of waterstriders (Gerridae: Hemiptera) with differing degrees of winglessness. Evolution, 35, 218-225. 